\title{
A Resistometric Study of the Configuration of Ag Atoms in Aluminum-1.03 at \% Silver Alloy
}

\author{
By Hiroto Osono*, Shuzo Kawata**, Toshiro Endo* \\ and Takao Kino***
}

\begin{abstract}
An apparatus for the precise measurement of electrical resistivity of aluminum alloys above room temperature has been constructed. The electrical resistivities of pure aluminum and of Al-1.03 at $\% \mathrm{Ag}$ alloy were measured from room temperature to $500^{\circ} \mathrm{C}$ in air to investigate the correlation between electrical resistivity and the configuration of $\mathrm{Ag}$ atoms in the alloy. The difference in resistivity between the pure aluminum and the $\mathrm{Al}-\mathrm{Ag}$ alloy changed markedly with the measuring temperature, and the behavior corresponds well to the quasi-equilibrium phase diagram of the alloy including G.P. zones. Furthermore, the result shows that the G.P. zones are formed not only in the presence of supersaturated vacancies but also at the equilibrium vacancy concentration during the slow cooling process.
\end{abstract}

(Received May 26, 1977)

\section{Introduction}

Extensive studies have been made on the clustering of solute atoms in alloys including the precipitation phenomena and the formation or resolution of Guinier-Preston zones (G. P. zones), etc. Most of the work has been dealt with changes in physical properties during the aging process after quenching. Many of the vacancies are frozen-in by the quenching, the supersaturated vacancies cluster by themselves and accelerate the solute clustering. Therefore, both property changes due to solute atoms and vacancies are imposed, and it is difficult to separate from each other. In usual metals such as aluminum, the diffusivities of solute atoms and vacancies are fairly large so the clustering and annihilation of these point defects occur even during the quenching. Then the configuration of solute atoms after the quenching differs from one before the quenching. Especially, in some aluminum alloys, the rate of G.P.

* Hiroshima Denki Institute of Technology, Hiroshima 739-03, Japan.

** Laboratory of Crystal Physics, Faculty of Science, Hiroshima University, Hiroshima 730. Present address: Faculty of Education, Saga University, Saga 840, Japan.

*** Laboratory of Crystal Physics, Faculty of Science, Hiroshima University, Hiroshima 730, Japan. zone formation is too fast to detect the process of zone formation ${ }^{(1)}$.

Therefore, it is interesting to study the process of formation of the G.P. zones and precipitation in the state near the thermal equilibrium at high temperature, in other words, to study the clustering process of solute atoms without the supersaturated vacancies.

The electrical resistance was selected as the physical property which was sensitive to the change in configuration of solute atoms at such high temperatures. However, the greater part of the resistance in metals at high temperatures is due to the lattice vibration, and the contribution from the solute atoms is very small in dilute alloys. Therefore, the highly precise measurements are required to detect the change in configuration of solute atoms. Little has been studied on the behavior of solute atoms in terms of electrical resistivity, except for the work of Hirano et al. ${ }^{(2)(3)}$ on $\mathrm{Al}-\mathrm{Zn}$ and $\mathrm{Al}-\mathrm{Cu}$ alloys. In their work the electrical resistance was measured as the sample was heated or cooled slowly at a constant rate. They found that the resistance in low temperature regions was a little higher than the one extrapolated from the higher temperature regions, and suggested that the supersaturated vacancy is not necessary to form the G.P. zones.

In order to detect phenomena with slow 
reaction rates, e.g. precipitation, an apparatus with which continuously measure the resistivity with high precision was constructed in the present work. Using the apparatus, the electrical resistance of $\mathrm{Al}-1.03 \mathrm{at} \% \mathrm{Ag}$ alloy was measured from room temperature to $500^{\circ} \mathrm{C}$ in the aim of investigating the change in configuration of $\mathrm{Ag}$ atoms in the alloy.

\section{Experimental Procedure}

\section{Specimen and the heat-treatment}

Specimens used in this experiment were a zone-refined aluminum (referred to as $\mathrm{ZR}-\mathrm{Al}$ ) and an $\mathrm{Al}-1.03$ at $\% \mathrm{Ag}$ alloy (referred to as $\mathrm{Al}-\mathrm{Ag}$ ), which were wires $0.3 \mathrm{~mm}$ in diameter. Details of the preparation of these wires were described elsewhere ${ }^{(4)(5)}$.

The length of the specimen was about 140 $\mathrm{cm}$, and both ends were served as the current leads. Two wires of the same material as the specimen were spot-welded to the specimen at intervals of about $27 \mathrm{~cm}$ (guage length) as the potential leads for the measurement of electrical resistance.

In order to reduce the dislocations and the other defects introduced by drawing, the specimens were annealed in air at $500^{\circ} \mathrm{C}$ for $3 \mathrm{~h}$ and cooled down to room temperature in an electric furnace. During the cooling, the resistance of the specimens was measured together with the temperature. The grain size of the $\mathrm{Al}-\mathrm{Ag}$ specimen was about $0.3 \mathrm{~mm}$ after the annealing.

After the furnace-cooling, these specimens were aged for about $1 \mathrm{~h}$ at different temperatures between room temperature and $500^{\circ} \mathrm{C}$. The aging temperature was raised from room temperature to $500^{\circ} \mathrm{C}$ step by step at temperature intervals of several or several tens of degrees and then lowered down to room temperature in the same manner. The two processes in which the aging temperature was raised or lowered will be referred to hereafter as the heating process and the cooling process, respectively.

\section{Temperature control}

Specimens were settled in an aluminum block which is shown in Fig. 1, to reduce the fluctuation of temperature, the contamination of

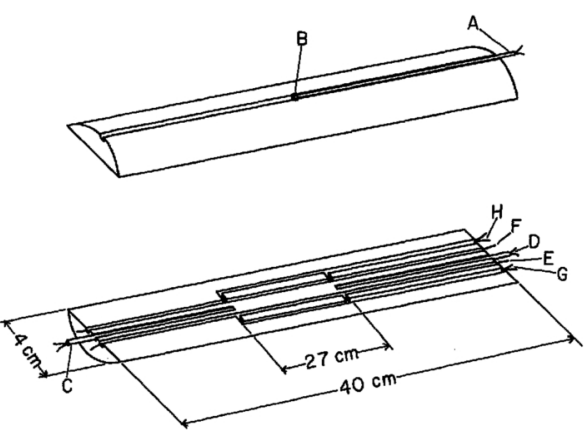

Fig. 1 Aluminum block in the furnace A: Thermocouple TC1, B: Small hole, C: Thermocouple TC2, D: Thermocouple TC3, E: Specimen ZR-Al, F: Specimen Al-Ag, G: Potential leads for $\mathbf{Z R}-\mathrm{Al}$, $\mathrm{H}$ : Potential leads for Al-Ag.

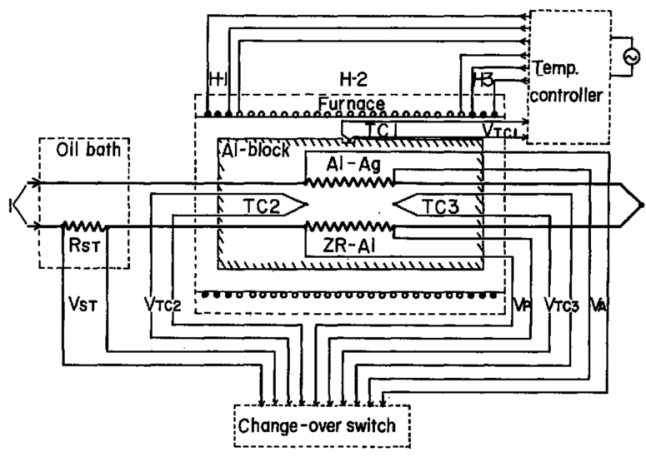

Fig. 2 Schematic diagram of the electric furnace, the temperature controller and the circuit for electrical resistance measurement.

specimens and the deformation due to their thermal contraction or expansion. The specimens were insulated from the aluminum block by alumina insulating tubes $(0.8 \mathrm{~mm}$ in inside diameter). The block was inserted into the electric furnace as shown in Fig. 2. The connecting point at which the two specimen wires ( $\mathrm{ZR}-\mathrm{Al}$ and $\mathrm{Al}-\mathrm{Ag}$ ) were connected by spotwelding was placed about $30 \mathrm{~cm}$ apart from the furnace and maintained at room temperature to eliminate the thermoelectromotive force in the current circuit and to suppress the diffusion of $\mathrm{Ag}$ atoms into $\mathrm{ZR}-\mathrm{Al}$ from the $\mathrm{Al}-\mathrm{Ag}$ alloy.

The temperature of specimens was controlled by an automatic temperature controller consisting of reference input elements, a multiposition controller and a regulator for the electric power to the furnace as illustrated in Fig. 3. The apparatus constructed by us could control 


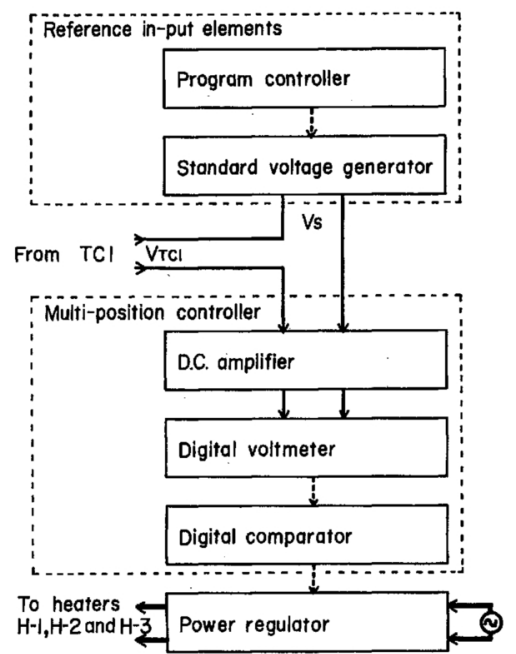

Fig. 3 Block diagram of the temperature controller.

the aging temperature by regulating the alternating current flowing into the furnace and automatically changing the aging temperature. The mechanism of temperature control is described below in details in connection with the construction and functions of the apparatus.

The temperature in the furnace was determined by a thermoelectromotive force $V_{\mathrm{TC} 1}$ of a chromel-alumel thermocouple TCl which was placed in a small hole of the groove at the surface of the aluminum block as shown in Fig. 1. The voltage $V_{\mathrm{TC} 1}$ was compared with the standard voltage $V_{\mathrm{S}}$ which corresponded to the desired temperature. The voltage $V_{\mathrm{S}}$ was given from a standard voltage generator and was automatically changed using a program controller. The difference $\left(V_{\mathrm{S}}-V_{\mathrm{TC} 1}\right)$ was transmitted to the multi-position controller with a sensitivity of $1 \mu \mathrm{V}$, which consisted of a dc amplifier, a digital voltmeter and a digital comparator, as shown in Fig. 3. In the multi-position controller, the difference $\left(V_{\mathrm{S}}-V_{\mathrm{TC} 1}\right)$ was amplified with the dc amplifier and converted to a digital form in the digital voltmeter. The converted digital form which was the number of pulses was compared with three levels of voltage $(0$, low, high) set up manually in the digital comparator. Based on the result of the comparison, one of the corrected signals (negative, low, middle or high signal) was transmitted to a power regulator which regu- (a)

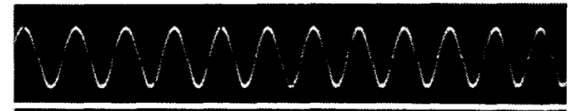

(b)

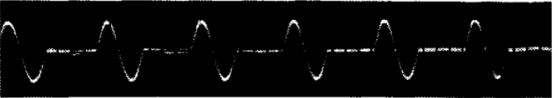

(c)

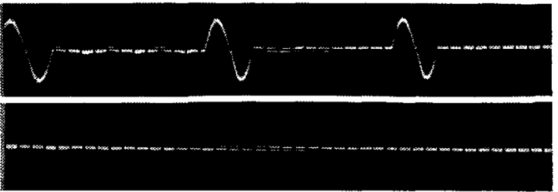

Photo. 1 Wave form of the alternating current to the heater. Wave forms (a), (b), (c) and (d) correspond to the corrected signals high, middle, low and negative, respectively.

lated the alternating current to the heater in the furnace. The power regulator contained a gatecontrolled semiconductor switch whose conduction time was determined by the number of alternating cycles per unit time which corresponded to the corrected signal as shown in Photo. 1. To reduce the noise in the usual phase control method, the alternating cycle was started from zero degree in the phase angle as seen in the photograph. To obtain the uniform temperature distribution in the furnace, the heater was separated into three parts ( $\mathrm{H}-1$, $\mathrm{H}-2, \mathrm{H}-3)$ as shown in Fig. 2 and the power to each heater was regulated independently.

Using the apparatus, the temperature of the specimen was maintained within $\pm 0.05^{\circ} \mathrm{C}$ during the aging, and the temperature difference between both ends of the gauge length of specimen was less than $0.1{ }^{\circ} \mathrm{C}$.

\section{Measurements of temperature and elec- trical resistance}

The temperature around the specimen was measured with two chromel-alumel thermocouples whose voltages were referred to as $V_{\mathrm{TC} 2}$ and $V_{\mathrm{TC} 3}$ respectively. Two thermocouples were mounted near both ends of the gauge length of the specimen in the aluminum block, as shown in Figs. 1 and 2.

Electric current through the specimen was about $80 \mathrm{~mA}$ supplied from a dc constantcurrent source. The precise value of the current was determined by the measurement of the voltage $V_{\text {ST }}$ of a standard resistor, which was connected in series with the specimen and 


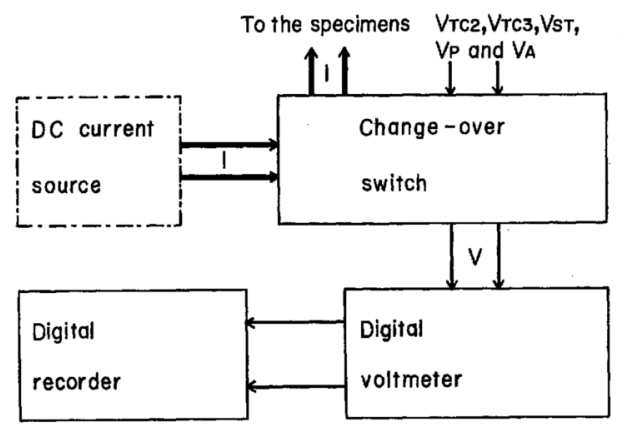

Fig. 4 Block diagram of the apparatus for voltage measurement.

placed in an oil bath as shown in Fig. 2.

The voltage between gauge length of specimens and thermocouples were measured quickly ( $0.5 \mathrm{~s} /$ time) with a digital voltmeter (Takeda Riken Industry Co., Ltd. TR-6515) and continuously recorded with a digital recorder as shown in Fig. 4. The voltage to be measured was selected automatically with a change-over switch constructed by us and transmitted to the digital voltmeter. The direction of the current through the specimen circuit was reversed by the change-over switch to reduce the thermoelectromotive force in the circuit in the following way. Firstly one of the voltages $V_{\mathrm{TC} 2}, V_{\mathrm{TC} 3}$, $V_{\mathrm{ST}}, V_{\mathrm{P}}, V_{\mathrm{A}}$ was selected by the change-over switch in the order at intervals of $3 \sim 14 \mathrm{~s}$. Then the direction of the current through the specimen was reversed, and the voltage measurements were made in the opposite order, and the mean value of both measurements were used as the correct value for each voltage. One set of these voltage measurements required $24 \mathrm{~s}$ at least.

The accuracy of the voltage measurements in this system was $0.01 \%$ of readings plus or minus $1.5 \times 10^{-6} \mathrm{~V}$, and it was possible to detect the temperature variation of $0.05^{\circ} \mathrm{C}$.

The conversion of the electrical resistance into the electrical resistivity was made in a similar way described before ${ }^{(5)}$. The value used as the resistivity at $300 \mathrm{~K}, \rho(300 \mathrm{~K})$, of the specimen was $2.733 \mu \Omega \mathrm{cm}$ and $3.172 \mu \Omega \mathrm{cm}$ for $\mathrm{ZR}-\mathrm{Al}$ and $\mathrm{Al}-\mathrm{Ag}$, respectively. In order to obtain the value of $R(300 \mathrm{~K})$ for each specimen, the specimens were annealed at $500^{\circ} \mathrm{C}$ for $3 \mathrm{~h}$ and furnace-cooled. During the furnacecooling, the resistance of the specimen was measured together with the temperature. The value of $R(300 \mathrm{~K})$ of each specimen was determined from a relation $R(T)=R(300 \mathrm{~K})$ $[1+\alpha \cdot \Delta T]$ using the values of the resistance $R(T)$ at the temperature near $300 \mathrm{~K}$, where $\alpha$ was the temperature coefficient of resistivity, which was $4.14 \times 10^{-3}$ and $3.54 \times 10^{-3} \mathrm{deg}^{-1}$ for $\mathrm{ZR}-\mathrm{Al}$ and $\mathrm{Al}-\mathrm{Ag}$, respectively.

\section{Experimental Results}

The electrical resistivity of $\mathrm{ZR}-\mathrm{Al}$ and $\mathrm{Al}-\mathrm{Ag}$ alloy after aging for about $1 \mathrm{~h}$ are plotted against the aging temperature $T_{\mathrm{A}}$ between room temperature and $500^{\circ} \mathrm{C}$ for both heating and cooling processes in Fig. 5. One set of the measurements of the temperature and the resistance of specimen was carried out at intervals of two minutes during the aging. Aging temperature $T_{\mathrm{A}}$ was changed at intervals of several or ten degrees. Aging temperature $T_{\mathrm{A}}$ was changed at intervals of several tens of degrees, but the resistivity change against $T_{\mathrm{A}}$ was similar to that in Fig. 5.

Figure 5 shows that the resistivity of $\mathrm{ZR}-\mathrm{Al}$, $\rho_{\mathrm{P}}$, changed monotonously against $T_{\mathrm{A}}$, and the

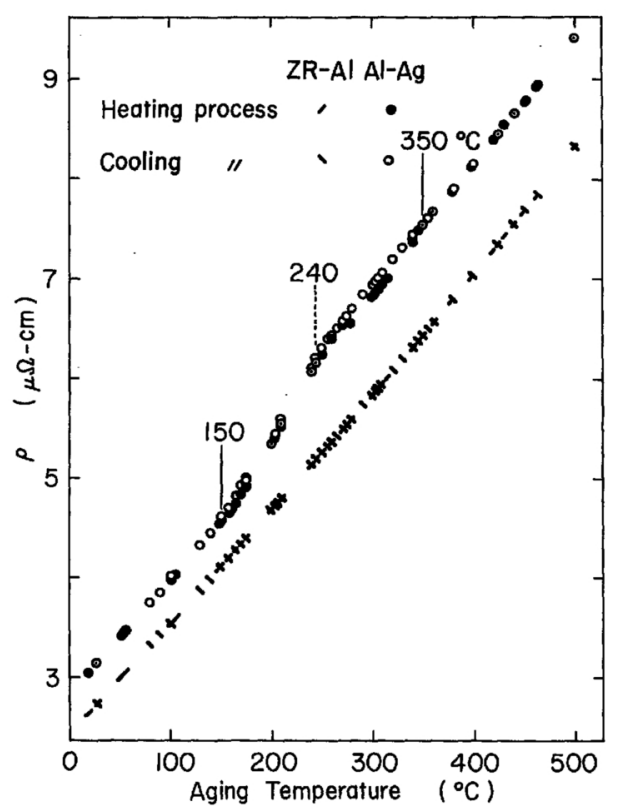

Fig. 5 The electrical resistivities plotted against the aging temperature $T_{\mathrm{A}}$ on $\mathrm{ZR}-\mathrm{Al}$ and $\mathrm{Al}-1.03$ at $\%$ $\mathrm{Ag}$ alloy after $1 \mathrm{~h}$ aging at $T_{\mathrm{A}}$. 
values of $\rho_{\mathbf{P}}$ in the heating process agreed well with those in the cooling process. On the other hand, the resistivity of $\mathrm{Al}-\mathrm{Ag}, \rho_{\mathrm{A}}$, was larger than $\rho_{\mathbf{P}}$ for all the aging temperatures $T_{\mathbf{A}}$, and showed a complicated behavior in comparison with $\rho_{\mathbf{p}}$. The characteristic feature was recognized in each region of the aging temperature which was region $\mathrm{I}$ (lower than $150^{\circ} \mathrm{C}$ ), region II (between 150 and $350^{\circ} \mathrm{C}$ ) and region III (above $350^{\circ} \mathrm{C}$ ). The temperature coefficient of $\rho_{\mathrm{A}}$ was slightly larger than that of $\rho_{\mathrm{P}}$ in region I. In the region III, the resistivity difference $\left(\rho_{\mathbf{A}}-\rho_{\mathbf{P}}\right)$ was considerably larger than that in region $I$, while the temperature coefficient of $\rho_{\mathrm{A}}$ was almost the same as that of $\rho_{\mathrm{P}}$.

In region II, $\rho_{\mathrm{A}}$ changed markedly with $T_{\mathrm{A}}$, and a considerable change in $\rho_{\mathrm{A}}$ was observed during the $1 \mathrm{~h}$ aging. For example, two open circles at $240^{\circ} \mathrm{C}$ in Fig. 5 show the initial and final values of $\rho_{\mathrm{A}}$ during the aging for $1 \mathrm{~h}$. Furthermore, hysteresis was observed between the heating and cooling processes. Now, the resistivity difference, $\Delta \rho=\rho_{\mathrm{A}}-\rho_{\mathrm{P}}$, was considered to be the contribution from $\mathrm{Ag}$ atoms in the alloy, and so $\Delta \rho$ is plotted against $T_{\mathrm{A}}$

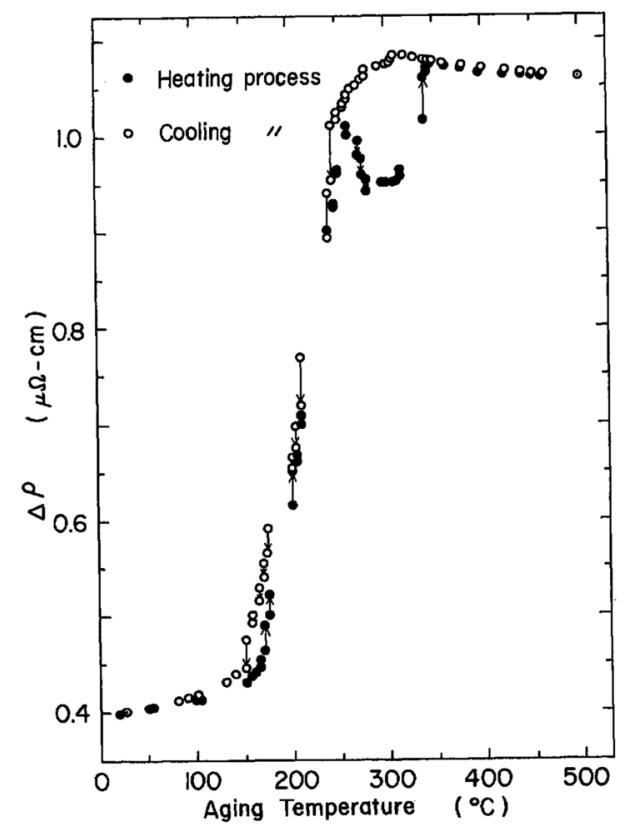

Fig. 6 The resistivity difference $\Delta \rho$ between $\mathrm{ZR}-\mathrm{Al}$ and $\mathrm{Al}-1.03$ at $\% \mathrm{Ag}$ versus $T_{\mathrm{A}}$. Vertical line shows the change in $\Delta \rho$ during $1 \mathrm{~h}$ aging and arrow shows the direction of the change. in Fig. 6. Vertical lines connecting two points in the figure show the changes in $\Delta \rho$ during aging for $1 \mathrm{~h}$, except the aging at $280^{\circ} \mathrm{C}$ and $150^{\circ} \mathrm{C}$ in the cooling process in which the aging times were 4 and $2 \mathrm{~h}$, respectively.

It can be seen in Fig. 6 that the variation in $\Delta \rho$ with $T_{\mathrm{A}}$ in region II was quite large in contrast with that in regions $I$ and III. In region $I$, the value of $\Delta \rho$ increased slightly with $T_{\mathrm{A}}$ from room temperature to $150^{\circ} \mathrm{C}$, and the value of $\Delta \rho$ in the heating process were almost the same as that in the cooling process. The value of $\Delta \rho$ in region III rather decreased with $T_{\mathrm{A}}$ in both heating and cooling processes.

Variation of $\Delta \rho$ with $T_{\mathrm{A}}$ was remarkable in region II. The temperature at which $\Delta \rho$ increased was higher in the heating process than that in the cooling process. In the temperature range from 150 to $240^{\circ} \mathrm{C}, \Delta \rho$ rapidly increased and decreased in the heating and cooling processes, respectively. The changing rate of $\Delta \rho$ with $T_{\mathrm{A}}$ was slightly larger in the temperature range from 200 to $240^{\circ} \mathrm{C}$ than that in the range below $200^{\circ} \mathrm{C}$ in both processes. At higher temperatures in region II, the value of $\Delta \rho$ in the heating process decreased with $T_{\mathrm{A}}$ to a minimum at $T_{\mathrm{A}}=300^{\circ} \mathrm{C}$ and then increased rapidly with $T_{\mathrm{A}}$ up to $350^{\circ} \mathrm{C}$, while in the cooling process $\Delta \rho$ decreased gradually with decreasing $T_{\mathrm{A}}$. Therefore, a remarkable difference in $\Delta \rho$ was observed between the cooling process and the heating process in the temperature range from 260 to $350^{\circ} \mathrm{C}$, and it was the most remarkable hysteresis in the $\Delta \rho-T_{\mathrm{A}}$ curve.

As described already, $\Delta \rho$ changed during the aging as seen in Figs. 7 and 8 for the heating and cooling process, respectively. In general, $\Delta \rho$ changed monotonously in these processes. However, for the aging at $251^{\circ} \mathrm{C}$ in the heating process, $\Delta \rho$ increased initially and then decreased monotonously as shown in Fig. 7 .

To clarify the change in $\Delta \rho$ with the aging time $t_{\mathrm{A}}$, the differences $\left(\Delta \rho_{t}-\Delta \rho_{t=0}\right)$ between the three representative aging time $t_{\mathrm{A}}$, i.e., 10 , 20 and $30 \mathrm{~min}$, and $t_{\mathrm{A}}=0$ are plotted against $T_{\mathrm{A}}$ for both processes in Fig. 9. The number in the figure shows the aging temperature at which $\left|\Delta \rho_{t}-\Delta \rho_{t=0}\right|$ is small after the aging for $30 \mathrm{~min}$.

From these results, the temperature region where $\Delta \rho$ shows the characteristic behavior 


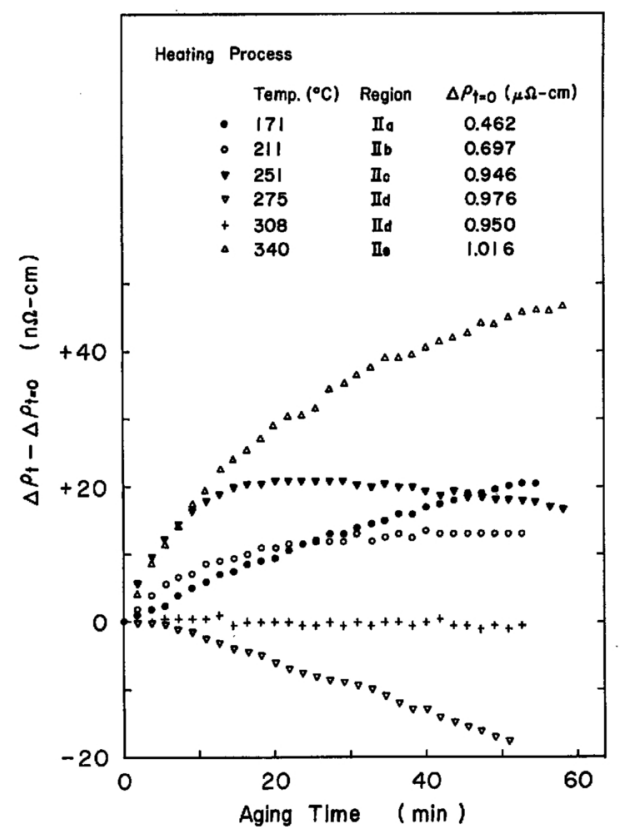

Fig. 7 The resistivity change during isothermal aging in the heating process.

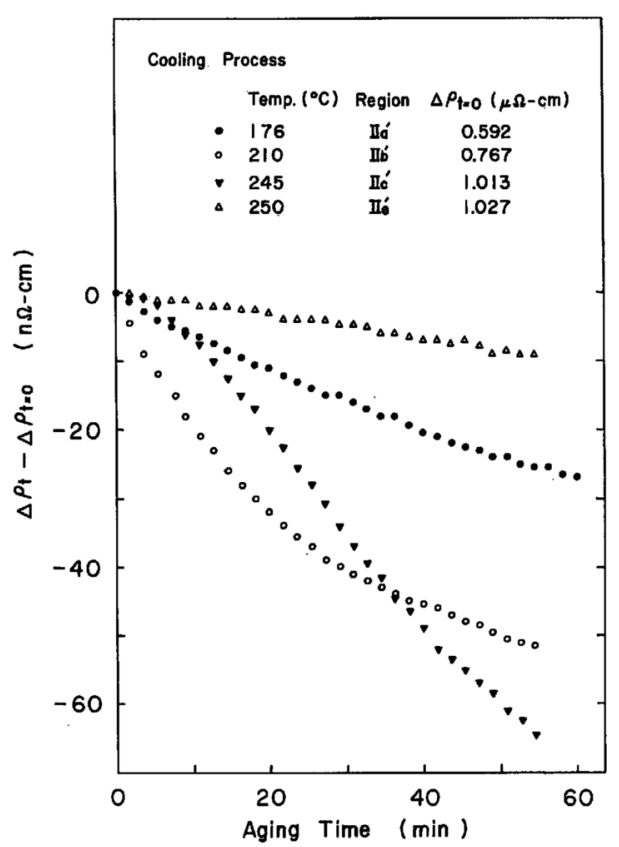

Fig. 8 The resistivity change during isothermal aging in the cooling process.

against $T_{\mathrm{A}}$ and $t_{\mathrm{A}}$ is classified as region $\mathrm{I}$ (room temperature $\sim 150^{\circ} \mathrm{C}$ ), IIa $\left(150 \sim 205^{\circ} \mathrm{C}\right)$, IIb $\left(205 \sim 240^{\circ} \mathrm{C}\right)$, IIc $\left(240 \sim 260^{\circ} \mathrm{C}\right)$, IId $(260 \sim$

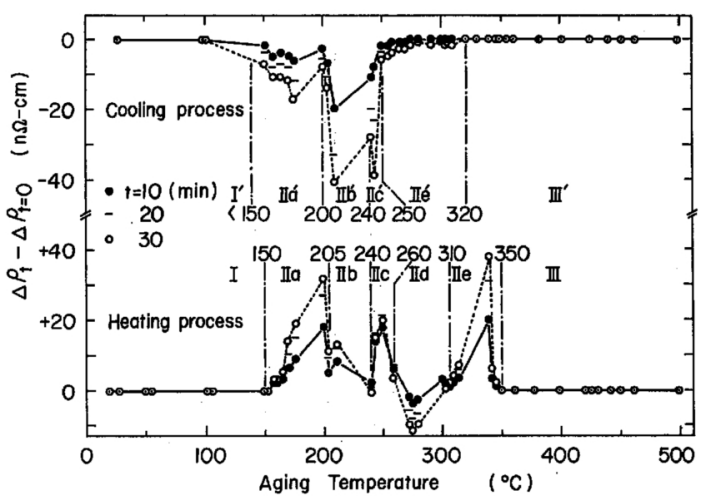

Fig. 9 The resistivity changes during isothermal aging at 10,20 and $30 \mathrm{~min}$ after the temperature changes. Symbol $(\odot)$ shows overlapping of two symbols $(\mathrm{O})$ and $(\odot)$, and means that the resistivity did not change during the aging.

$\left.310^{\circ} \mathrm{C}\right)$, IIe $\left(310 \sim 350^{\circ} \mathrm{C}\right)$ and III $\left(350 \sim 500^{\circ} \mathrm{C}\right)$ in the heating process, and the region III $^{\prime}$ $\left(500 \sim 320^{\circ} \mathrm{C}\right), \mathrm{II}^{\prime} \mathrm{e}\left(320 \sim 250^{\circ} \mathrm{C}\right), \mathrm{II}^{\prime} \mathrm{c}(250 \sim$ $\left.240^{\circ} \mathrm{C}\right), \mathrm{II}^{\prime} \mathrm{b}\left(240 \sim 200^{\circ} \mathrm{C}\right), \mathrm{II}^{\prime} \mathrm{a}\left(200 \sim 150^{\circ} \mathrm{C}\right)$ and $\mathrm{I}^{\prime}\left(150^{\circ} \mathrm{C} \sim\right.$ room temperature $)$ in the cooling process.

\section{Discussion}

The resistivity change in $\rho_{\mathrm{A}}$ during aging can be explained by the change in configuration of $\mathrm{Ag}$ atoms in the alloy. In the regions III and III' $\mathrm{Ag}$ atoms are resolved in the alloy, because $\Delta \rho$ is almost constant over the region, and furthermore $\Delta \rho$ at a given aging temperature does not change during the isothermal aging. This is well understood from the phase diagram by Rotherham and Larke ${ }^{(6)}$, as shown in Fig. 10. In the diagram, the solvus of the $\mathrm{Al}-\mathrm{Ag}$ alloy intersects the line for 1.03 at $\% \mathrm{Ag}$ at $328^{\circ} \mathrm{C}$. In the present experiment, however, the temperature at which $\Delta \rho$ attains to a constant value is $350^{\circ} \mathrm{C}$ in the heating process and $320^{\circ} \mathrm{C}$ in the cooling process, which deviates from $328^{\circ} \mathrm{C}$. It is considered that the deviation arises from superheating or supercooling. Now, the small decrease in $\Delta \rho$ above $350^{\circ} \mathrm{C}$ seems to be a temperature dependence of the resistivity due to the isolated $\mathrm{Ag}$ atoms, that is, a deviation from Matthiessen's rule. A similar temperature dependence has been observed at temperatures below $300 \mathrm{~K}$ in a quenched $\mathrm{Al}-1.03$ 


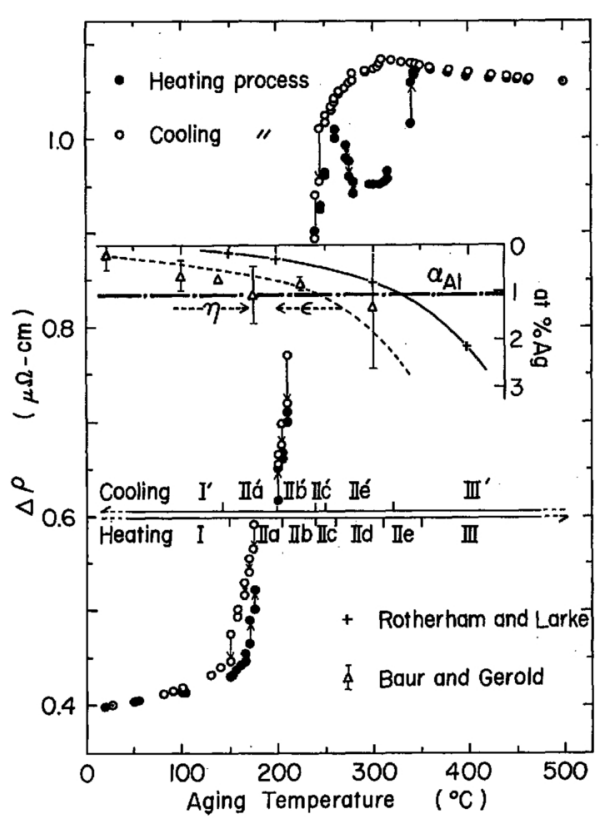

Fig. 10 The same figure as in Fig. 6 with the solubility limit (solid line), the solvus of G.P. zone (dotted line) and the temperature regions classified in text.

at $\% \mathrm{Ag}$ alloy, and explained by the deviation from Matthiessen's rule ${ }^{(7)}$. Thus, the regions III and III' correspond to the state of solid solution in the phase diagram. However, the region below $350^{\circ} \mathrm{C}$, especially the rapid decrease in $\Delta \rho$ during the early stage of isothermal aging, cannot be explained simply by the precipitation of the $\gamma$ phase from the $\alpha$ solid solution or vice versa. It is necessary to take into account the formation and resolution of small solute clusters and the G.P. zones in the process of precipitation and resolution of $\gamma$-phase from $\alpha$-phase or vice versa. Especially, the rapid increase in $\Delta \rho$ with $T_{\mathrm{A}}$ which is observed in the regions IIb and IIc in the heating process is explained by resolution of the G.P. zones. Similarly, the rapid decrease in $\Delta \rho$ with $T_{\mathrm{A}}$ which is observed in regions $\mathrm{II}^{\prime} \mathrm{b}$ and $\mathrm{II}^{\prime} \mathrm{c}$ in the cooling process is attributed to the formation of the G.P. zones. Figure 10 shows part of the metastable miscibility gap of $\mathrm{Al}-\mathrm{Ag}$ alloys determined by Baur and Gerold ${ }^{(8)}$, together with the equilibrium phase diagram. Baur and Gerold have reported that the G.P. zones are in the $\eta$-state characterized by an ordered ar- rangement of atoms below $175^{\circ} \mathrm{C}$ and are in the $\varepsilon$-state characterized by a disordered arrangement above $220^{\circ} \mathrm{C}$.

Now, let us consider the configuration of $\mathrm{Ag}$ atoms in the temperature regions I and II. The solvus line of the $\gamma$-phase intersects the line for 1.03 at $\% \mathrm{Ag}$ at $328^{\circ} \mathrm{C}$ as seen in Fig. 10, so the precipitates ( $\gamma$-phase) are formed in the temperature region $\mathrm{II}^{\prime} \mathrm{e}$ in the cooling process. In the region $\mathrm{II}^{\prime} \mathrm{e}$, the decay rate of $\Delta \rho$ versus $t_{\mathrm{A}}$ is slow as seen from the isothermal aging curve at $250^{\circ} \mathrm{C}$ in Fig. 8 , so the precipitation rate seems to be slow. Abbott and Haworth have pointed out that a prolonged aging time is necessary to establish the equilibrium composition of the $\alpha$ and $\gamma$-phases ${ }^{(9)}$. Therefore, the rapid decrease of $\Delta \rho$ observed in the region II'c cannot be explained without the formation of the G.P. zones. In other words, the alloy achieves a supercooled state in the region II'e in the cooling process, and the supersaturated $\mathrm{Ag}$ atoms in the $\alpha$-phase start abruptly to form the G.P. zones as the temperature is lowered below $245^{\circ} \mathrm{C}$. Such a rapid decrease of $\Delta \rho$ is observed not only in the case in which it takes about $30 \mathrm{~h}$ to cool down the specimen from 500 to $245^{\circ} \mathrm{C}$ as described above, but also in the case in which it takes about $4 \mathrm{~h}$ as seen in Fig. 11.

Furthermore, $\Delta \rho$ during the isothermal aging shown in Figs. 7 and 8 approaches to constant value in the regions IIb and $\mathrm{II}^{\prime} \mathrm{b}$, but in the regions IIa and II'a such a tendency does not observed. In the regions $I$ and $I^{\prime} \Delta \rho$ hardly changes as seen in Fig. 9. These facts consist with the following conclusions in the X-ray study for quenched Al-Ag alloy by Baur and Gerold $^{(8)}$. The concentration of Ag atoms in the G.P. zones changes rapidly as the aging temperature changes above $100^{\circ} \mathrm{C}$, and the transformation between $\eta$-state and $\varepsilon$-state occurs between 175 and $220^{\circ} \mathrm{C}$. Then, it is concluded that the G.P. zones in the region $\mathrm{I}\left(\mathrm{I}^{\prime}\right)$ is the $\eta$ state, and one in the region $\mathrm{IIb}\left(\mathrm{II}^{\prime} \mathrm{b}\right)$ is the $\varepsilon$ state, and that the transformation between $\eta$ state and $\varepsilon$-state occurs in the region IIa(II'a).

The rapid increase in $\Delta \rho$ between 240 and $260^{\circ} \mathrm{C}$ in the heating process in Fig. 10, i.e. the region IIc in Fig. 9, is explained by the resolution of the G.P. zones. This process is also 


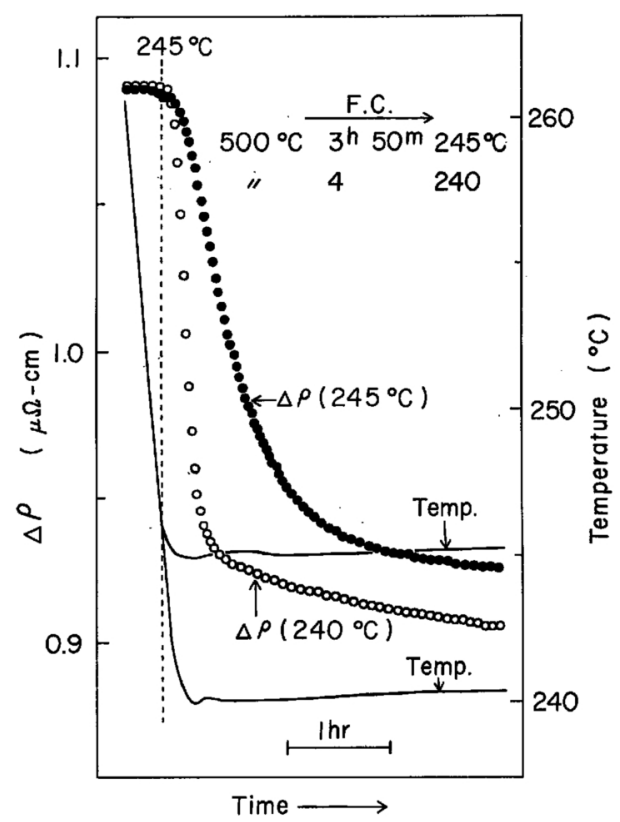

Fig. 11 Changes in resistivity difference $\Delta \rho$ and temperature during furnace cooling (F.C.) from $500^{\circ} \mathrm{C}$ to each aging temperature.

seen in the isothermal aging curve at $251^{\circ} \mathrm{C}$ in the heating process in Fig. 7.

Furthermore, the decrease in $\Delta \rho$ in the region IId corresponds to the precipitation of supersaturated $\mathrm{Ag}$ atoms to form the $\gamma$ phase and the increase in $\Delta \rho$ in the region IIe is attributed to the resolution of the precipitates.

As described above, the resistivity change in the $\mathrm{Al}-\mathrm{Ag}$ alloy is understood taking into account the formation and resolution of the
G.P. zones during the aging at such high temperature. During such a slow cooling process in which vacancies are almost in thermal equilibrium, the G.P. zones are formed around $245^{\circ} \mathrm{C}$, and almost all of them remain as the zones during the aging at lower temperatures. However, the transformation between $\varepsilon$-state and $\eta$-state occurs at the regions IIa and II'a. The zones resolve again by the heating above $245^{\circ} \mathrm{C}$.

\section{Acknowledgments}

Two of the authors (H.O. and T.E.) express their gratitude to Profs. Katsuo Kobayakawa and Tamotsu Yasumoto of Hiroshima Denki Institute of Technology for the continuous encouragement.

\section{REFERENCES}

(1) K. N. Murty and K. I. Vasu: Mater. Sci. Eng., 5 (1969/70), 251.

(2) K. Hirano and H. Hori: J. Japan Inst. Metals, 36 (1972), 97; ibid., 37 (1973), 135.

(3) H. Hori and K. Hirano: J. Japan Inst. Metals, 37 (1973), 142.

(4) T. Kino et al.: Trans. JIM, 17 (1976), 645.

(5) S. Kawata and T. Kino: J. Phys. Soc. Japan, 39 (1975), 684.

(6) L. Rotherham and L. W. Larke: J. Inst. Metals, 81 (1952/53), 67.

(7) S. Kawata: J. Sci. Hiroshima Univ., Ser. A, 40 (1976), 43.

(8) R. Baur and V. Gerold: Acta Met., 10 (1962), 637.

(9) K. Abbott and C. W. Haworth: Acta Met., 21 (1973), 951. 